Document downloaded from:

http://hdl.handle.net/10251/78099

This paper must be cited as:

García Sanjuan, F.; Jaén Martínez, FJ.; Nácher-Soler, VE.; Catalá Bolós, A. (2015). Design and Evaluation of a Tangible-Mediated Robot for Kindergarten Instruction. ACM. doi:10.1145/2832932.2832952.

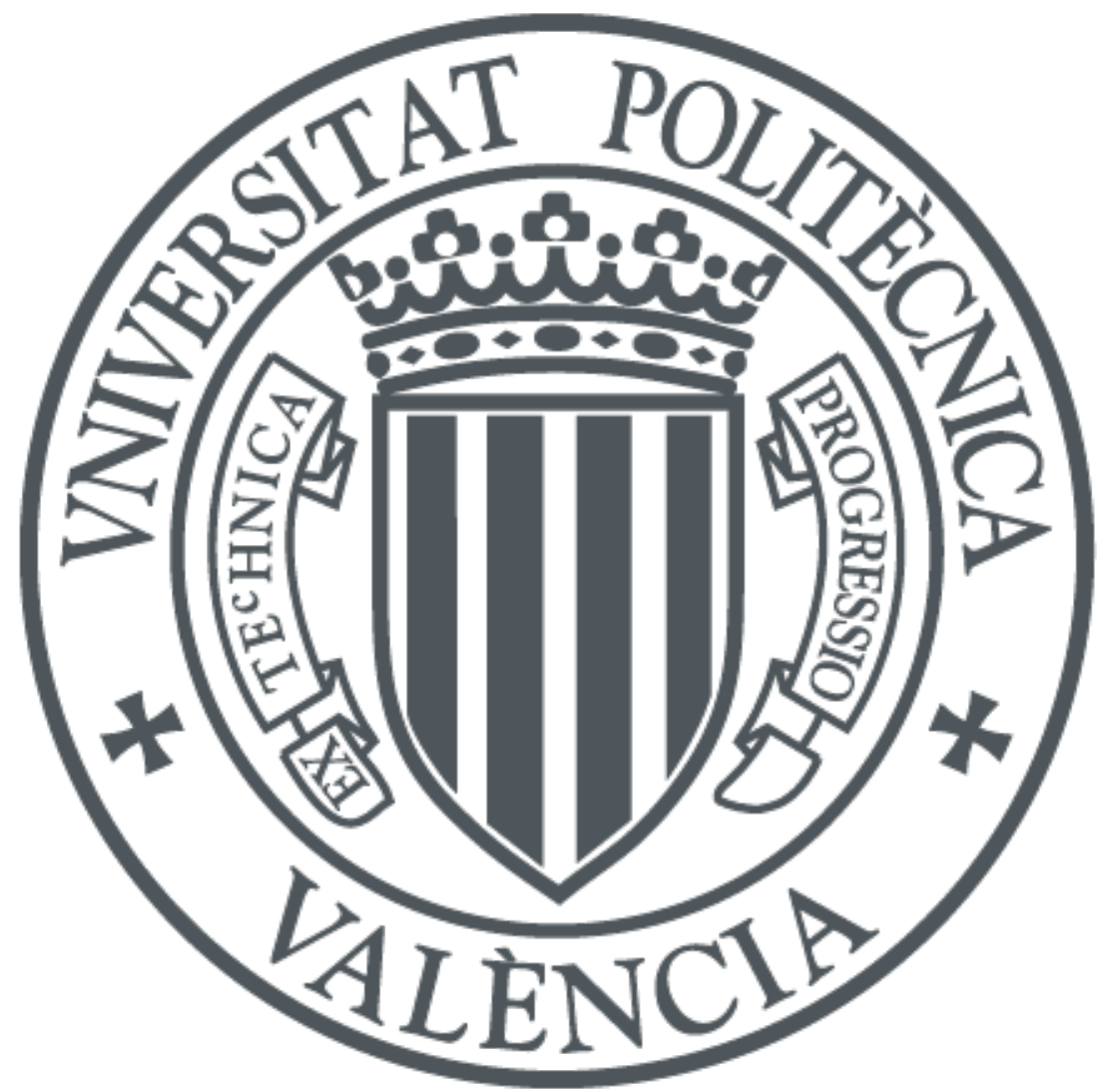

The final publication is available at

http://dl.acm.org/citation.cfm?id=2832952

Copyright ACM

Additional Information

(C) ACM 2015. This is the author's version of the work. It is posted here for your personal use. Not for redistribution. The definitive Version of Record was published in ACE '15 Proceedings of the 12th International Conference on Advances in Computer Entertainment Technology.

http://dx.doi.org/10.1145/2832932.2832952 


\section{Design and Evaluation of a Tangible-Mediated Robot for Kindergarten Instruction}

\author{
Fernando Garcia-Sanjuan ${ }^{1}$ \\ fegarcia@dsic.upv.es \\ Javier Jaen ${ }^{1}$ \\ fjaen@upv.es \\ ${ }^{1}$ ISSI/DSIC, Universitat Politècnica de València \\ Valencia, Spain
}

\author{
Vicente Nacher ${ }^{1}$ \\ vnacher@dsic.upv.es \\ ${ }^{2}$ LoUISE/I3A, University of Castilla-La Mancha \\ Albacete, Spain
}

\begin{abstract}
Entertainment technology increases children's engagement in educational activities designed to develop abilities ranging from collaborative problem-solving and cognitive attention to self-esteem. However, little research has been done on designing educational and entertaining interactive technology for kindergarten children (up to 5 years old). Furthermore, most of the work in this area has considered traditional input devices such as the mouse and keyboard, which are not suitable for these very young children. More recently, other more intuitive means of interaction (touch and tangible interfaces) and advanced educational artifacts such as robots have emerged. In this work we therefore present a joint collaboration between technologists and kindergarten instructors to design and evaluate a technological platform using a mobile robot for kindergarten instruction, as well as an intuitive and user-friendly tangible user interface. The results obtained suggest the platform is not only usable by kindergarten children, but it also allows them to be fully immersed in a feeling of energized focus, full involvement, and enjoyment in the process of the activity. In addition, the instructors reported that the system was well accepted and praised its versatility in use as a supporting tool for their everyday classroom activities.
\end{abstract}

\section{Author Keywords}

Kindergarten; Child-Computer Interaction; Tangible User Interface (TUI); robots; iterative design; evaluation

\section{ACM Classification Keywords}

H.5.2. Information interfaces and presentation (e.g., HCI): User Interfaces - Interaction styles, Prototyping

\section{INTRODUCTION}

Children today are born in a technological era and are introduced to technology at a very early age. As a result, there are many examples that have proven the virtues of technology in even the earliest stages of learning programs. Entertainment technology in particular increases children's engagement in educational activities and kids using computers may acquire pro-social behaviors and develop collaborative problem-solving abilities, cognitive attention, and selfesteem [15].

Even though considerable research in this area involves primary school children (aged 6 to 11 years) [1,2,36], less attention has been paid to (pre-)kindergarten (up to 5 years old) users, perhaps because their cognitive and motor skills are not mature enough to be participants in interactions with computers via traditional peripherals such as mouse and keyboard. However, in recent years, more direct and intuitive means of interaction for children have been sought and these have been mainly enabled by touch interfaces $[9,19]$ and Tangible User Interfaces (TUIs), which present an added value in early childhood education "as they resonate with traditional learning manipulatives" [28]. On the other hand, the use of robots as an educational tool is gaining momentum. As Li et al. [14] point out, robots capture the imagination of children and, consequently, "using robots to support teaching and learning [...] has become a popular research topic". Nevertheless, very few studies in this area target children as young as those considered in this paper. This motivates us to carry out further studies that contribute to understanding the challenges, limitations and opportunities of these technologies in the context of kindergarten learning.

In this context, this work presents a technological platform aimed at supporting learning activities for kindergarten children using a TUI based on graspable interactive elements and a mobile robot. The platform was designed iteratively in two phases. Phase 1 consisted of building the first version of the prototype after a preliminary discussion between the design team and educational research specialists on the basic technological features a tangible-robotic infrastructure should have. The goal of this prototype was to serve as a starting point for Phase 2 , which involved interviews with nursery educators, who proposed alternative designs in order to make it more suitable for the target users and to facilitate educational scenarios that had not been envisioned previously. Another version of the prototype emerged from these two phases, which was then evaluated through an experiment with children from two local kindergartens in order to assess its usability and the impressions and behaviors observed in the participating children. Since several studies reveal gender differences in young children with respect to visual-spatial (e.g., $[13,18]$ ) and problem solving (e.g., [36]) skills, the experiment studied whether boys and girls performed and reacted differently with/to the platform.

The results obtained suggest the platform can be used by kindergarten children, who were found to enjoy using the system and had high levels of flow [20]. The instructors also reported that it was well accepted and praised its versa- 
tility as a supporting tool for their everyday classroom activities.

In sum, this paper contributes to the field by providing an evaluation of a mobile robot controlled by user-friendly tangible elements in the context of kindergarten settings. Also, it reports instructors' insights about design requirements for such a platform and about the activities that can be conducted with it.

\section{RELATED WORK}

The present work is influenced by previous research on Child-Computer Interaction. Traditionally, this area has focused on interaction with computers and, therefore, via the keyboard and mouse. Hourcade et al. [8], for instance, study the impact of mouse size on precision tasks concluding that when designing for very young children one should devise specific interactions taking into account that their motor skills are not yet fully developed. Another similar experiment conducted by Liu [15] concludes that, even though kids interact fairly well with the mouse, this device is not very intuitive for them since they instinctively try to make touch gestures on the computer screen. In a similar direction, Antle et al. [2] make a comparison between mouse-based and tangible interfaces to identify interaction patterns in children solving a spatial task. They observe that TUIs enable more exploratory actions, which in turn provide faster and easier ways of interaction.

On the other hand, others have explored in depth tangibleonly interactions with children. Dekel et al. [4] suggest that digitally augmenting a physical game such as using blocks to help children's spelling may have a positive effect on kids' enjoyment. Africano et al. [1] present the design of an interactive table with tangible tools to foster co-located collaboration, which they identify as a key element for learning that has not been explored in detail. Their platform is evaluated by teachers but who do not participate in the design phase. As a result, some activities are estimated to be too complex for children, but the authors do not present an alternative design. In turn, Marco et al. [16] also present a tangible-mediated tabletop for kindergarten instruction which is reported to trigger positive reactions from the children. With this platform, the kids engage in co-located activities by manipulating physical toys that have a fiducial marker attached that is recognized by the computer vision software of the tabletop. Although children were involved in the design process as testers, the teachers did not participate in this phase. Another interesting study is presented by Tsong et al. [34] who propose a design for a tangible multimedia learning system in which QR codes are attached to objects the children are already familiar with. Children are induced to show the tagged elements to the camera of a laptop and, as a result, some appropriate related content is displayed on the screen. Their study concludes that their platform enhances children's enjoyment and learning performance.
Finally, there are other works that analyze the use of robots in early childhood education. Osada et al. [21] present PaPeRo, a robot that could be used as a tool to teach manners, communication, etc. to elementary school children. Tanaka et al. [30] present QRIO, a humanoid robot aimed at encouraging toddlers to move and dance. However, their interaction with the robot is very limited, and as their only task is dancing, the proposed platform is limited in terms of learning activities it may enable. Another interesting work by Soute and Nijmeijer [27] presents an owl-shaped robot that plays story-telling games with children aged 4 to 6 . The robot narrates a partial story which children must complete by showing some flashcards to it. The results of the game sessions show that the system is engaging for kids. Ghosh and Tanaka [7] present a Care Receiving Robot (CRR) that adopts the role of the pupil and children act as teachers in order to learn English vocabulary. The experiments show that children are very motivated at first but tend to feel frustrated and bored if the robot gives right or wrong answers too often. Later, Tanaka and Matsuzoe [31] suggested that, in general, learning is enhanced if the CRR is used and concluded that this robot is able to teach verbs to kids aged 3 to 6 . In addition, besides training linguistic abilities, Tanaka and Takahashi [29,32] design a TUI in the form of a tricycle to remotely control a robot, which, as suggested in [17], could be used to develop spatial capabilities in young children. The authors later conduct an experiment [29] in order to evaluate the intuitiveness of the interface with respect to a video game controller, and conclude that, even though the participants were able to complete more tasks with the tricycle, no significant differences were found in terms of preferences between both tangible interfaces.

The above analysis reveals, firstly, a trend of usually considering interactions based on mechanisms other than tangible and robotic elements. Secondly, it shows that most works tend to focus on children aged 4 and over when considering their interaction with technology. Thirdly, it makes clear that instructors are not always participants in the design process of technology-based instruction environments. However, in our opinion they are a fundamental element who can provide a valuable contribution from their practical experience for the successful development of future kindergarten educational systems.

This work is a step forward in this direction and contributes to the field by evaluating an initial collection of design rationales obtained in close collaboration with kindergarten instructors and that should be taken into consideration when devising future learning ecosystems based on tangible and robotic elements for kindergarten children.

Our work shares several similarities with the commercial robot Bee-bot ${ }^{1}$, which consists of a bee-shaped programmable robot that can move around the floor. Bee-bot accepts movement commands by pressing some arrow buttons on

\footnotetext{
${ }^{1}$ https://www.bee-bot.us/
} 
its back. However, in our opinion, its control interface presents an elevated cognitive load that could be an issue for its use with children less than 4 years old. First, in order to give it a movement command, at least two actions are required (one to select the direction and then press the "go" button); and, second, since the robot only traverses a short distance per command, should the children want to make it follow a long path, they would be required to give many more commands. Additionally, the platform can only move following straight lines, because it only supports $90^{\circ}$ turns, and cannot support very well simultaneous interactions because of its limited interaction space and its incapacity to accept simultaneous commands. In addition, our design allows the specification of tangible elements with RFID tags encoding a pre-programmed set of sequential movement commands.

\section{PLATFORM DESIGN}

\section{Phase 1: Initial Prototype}

The design of the first prototype emerged from discussions between the design team and educational research specialists in order to obtain an initial concept design that would trigger further discussion about the actual requirements for the final platform. The first design iteration analyzed the best strategies to support Lentz et al.'s guidelines [10], which suggest technology for children should: a) support children's mobility, b) provide interaction with the real world, c) enable socialization, d) allow adult supervision and intervention, e) provide a variety of sensorial experiences, f) offer symbolic play (i.e, using objects, actions, or ideas as a form of representation), and g) limit children's exposure to the device.

As a result, the first design consisted of two major components: a mobile robot and some small cards as a tangible mechanism to communicate with. The cards (see Figure 1) consist of two small laminated sheets with an RFID tag in between, which encodes movement orders (move forward, stop, turn left, turn right) that are given to the robot by bringing them close to its RFID reader (see Figure 2). The robot was constructed using the Lego ${ }^{\mathrm{TM}}$ Mindstorms ${ }^{\circledR}$ Ev3 platform, which facilitates rapid prototyping of multiple versions. It communicates by means of a Bluetooth link with an external mobile phone connected to an RFID reader. The phone is able to process the RFID tags enclosed in

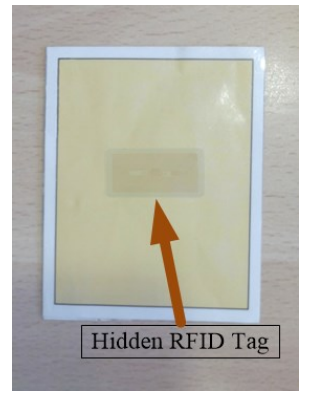

Figure 1. Card used to interact with the robot

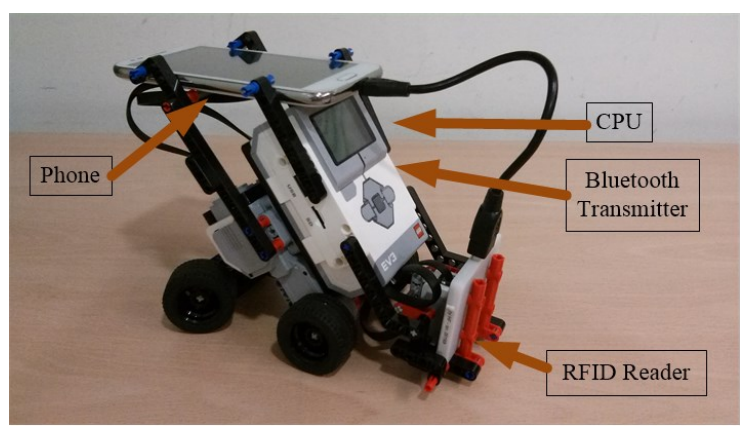

Figure 2. Detail of preliminary version of the robot

the cards, produces visual feedback and sends movement control commands to the robot by a Bluetooth link.

Phase 2: Review Sessions with Instructors and Design Refinement

Unstructured interviews were conducted with twenty-five educators from three different nurseries in order to obtain some insights into the design of the platform and the requirements to make it suitable for kindergarten environments. The participants had on average 17.27 years of experience $(\mathrm{SD}=10.33)$ in the field of kindergarten education, ranging from 3 to 36 years and all were females. They were organized into seven discussion groups in which the procedure was as follows: Firstly, they were introduced to the different parts of the platform. They then watched a running application in which a card was shown to the robot which started to move until a different card made it stop. After the demo, they were asked open questions regarding the design of the different components of the prototype to encourage group discussion. These conversations were recorded and subsequently analyzed.

All the educators participating in the interviews expressed concerns about children dismantling the robot and putting the pieces into their mouths. As one teacher pointed out, "kids really have to touch everything". Some of them were also worried about the fragility of the robot (e.g., "this robot in my class wouldn't last a day"). And some advised us to change its appearance to make it more appealing to children. The following solutions were proposed:

- Make the robot more robust and safe by enclosing it in a protective plastic case.

- Equip the robot with a pretty costume to give it a friendly plush toy-like look.

- Give the children a similar looking plush toy for them to manipulate, and bond with, which they can hold as they watch the actual robot move.

- Enable the robot to play audio files (music and sounds).

- Embed the RFID tags into "more manipulative" objects or change the materials of the cards into something "nicer" than plastic.

A second version of the prototype was produced after considering these comments. The cards were replaced by distinctive figures made of EVA foam, which contain the 


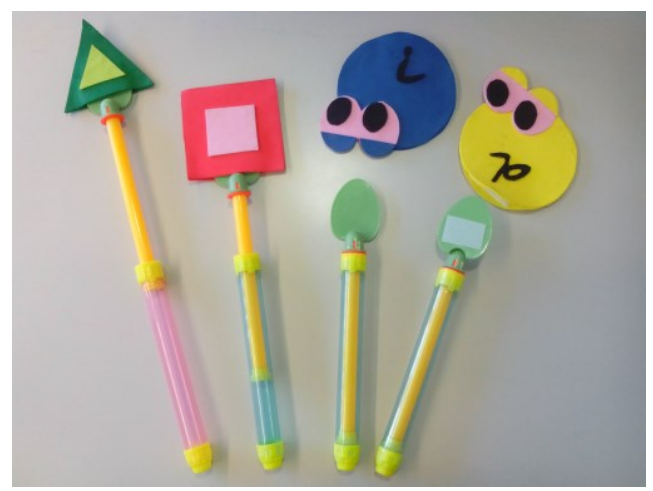

Figure 3. Sticks with shapes representing the commands for the robot. From left to right: move forward (green), stop (red), turn left (blue), and turn right (yellow).

RFID tag. These shapes can be attached to sticks by Vel$\mathrm{cro}^{\circledR}$ strips (see Figure 3) to make it easier for the kids to bring the shapes closer to the RFID reader. The commands these sticks represent, as can be seen in the figure from left to right, are: move forward, stop, turn left, and turn right. The proposed representations were obtained after discussions with educators who suggested that a representation based on shapes and colors would be favorable because these concepts were being taught to children. Besides, the use of arrows as a mechanism to describe turning commands was discarded because sticks could be approached to the robot from different points and with different rotations. As Figure 4 depicts, the robot's design was also modified by protecting it with a plastic case and attaching a Disney Wall-E plush robot to it. The RFID reader was moved outside the box and attached to the stuffed robot so that the kids could give it commands by putting the sticks to WallE's "chest".

\section{POTENTIAL EDUCATIONAL ACTIVITIES}

Besides the refinement of the platform's design, another result of the unstructured interviews with kindergarten educators was a discussion about whether the proposed robot and TUI could be used effectively in their everyday classes. In this respect, they found two different sets of activities that could be conducted with the platform, one for

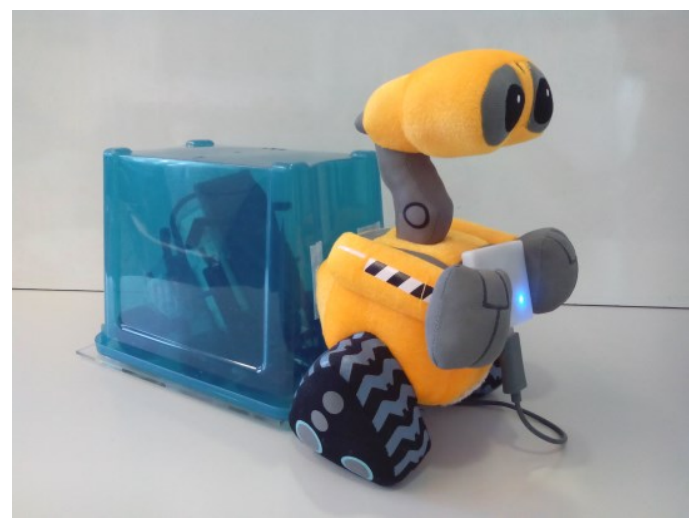

Figure 4. Phase 2 version of the robot the youngest children (aged from 24 to 42 months), and another for the older ones (aged 43-60 months). They did not think such technology was appropriate for kids less than 24 months old. Specifically, tasks for the youngest should be more focused on psychomotricity and sensorial experiences (e.g., touching, tasting, smelling, etc.), whereas the activities envisioned for older kindergartners could involve more complex cognitive skills such as establishing mappings between concepts.

There are several common requirements for both age groups, such as supporting activities for language learning (e.g., by playing songs), and giving the option to undo or correct a given action. The requirements specifically proposed by the instructors for children aged under 42 months suggest, firstly, that the activities should have a very short duration, because children often switch their attention to other stimuli of the environment; secondly, that these activities should involve small groups (up to four or five kids) in order to have all children under supervision; and, finally, as stated by one educator, "the activities should focus on these three basic concepts: movement, lights, and sound". Some examples of activities pointed out by the instructors that could be conducted with the youngest age group are:

- Teaching children what a robot is and how it moves. They could watch the actual robot while playing with their own plush toy proxy.

- Teaching children where the source of a given sound is by driving the robot to its apparent location.

- Using a card or a tangible object that represents a concept (colors, animals, etc.) and making the robot find a representation of this element in the classroom (e.g., a plush toy). In this case, the robot may be either directly controlled by children or able to move autonomously.

- Training psychomotor skills by making the robot move, possibly reproducing a sound to attract the attention of the children, and stimulate them to follow it. According to the instructors, this scenario could also be useful to teach children concepts such as "move/stop", "quick/slow", or "forwards/backwards", as they had seen the robot do during the demonstration.

Alternatively, teachers found additional more complex cognitive stimulation activities that could be supported with this technology for children in the second age group. In this case, the proposed size of the groups was increased to 7-9 kids. The educational activities suggested by the educators that could be performed with the platform can be summarized as follows:

- Moving the robot and making children repeat the movements afterwards. This could be done in the context of storytelling activities where, for example, the robot is looking for treasure and the kids must remember where the treasure is and repeat the robot's movements.

- Helping children associate concepts by placing some target objects on the floor and make them guide the ro- 
bot towards one specific target. The selection of the element to be found could be done by the teacher telling them what to look for, or by making the robot reproduce a sound for the kids to identify. This way many concepts could be taught, such as colors, animals, professions, shapes, means of transport, etc. As one teacher expressed, in concept-association tasks "you can do anything, everything!"

- A path could be drawn on the floor for the kids to follow in order to teach balance, with the robot in front to motivate them.

- Teaching children how to make the robot move by remote control from a tablet or phone.

\section{EVALUATION}

After finishing the second version of the prototype, it received the approval of the educators, and evaluation sessions were conducted to assess whether the children could effectively control the movement of the robot using the sticks. According to Druin's categorization of the various participatory roles children can have in the design of new technology [6], our participants acted as users/testers. The study consisted of several play sessions in which observational findings were recorded.

\section{Participants}

Sixty kindergarten children participated in this study with ages ranging from 26 to 53 months. Their average age was 38.17 months $(\mathrm{SD}=5.94)$. Since several studies have found differences between young boys and girls in terms of performance in visual-spatial and problem-solving tasks $[13,18,36]$, the children were classified by gender and arranged in groups of four boys or four girls. As a result, fifteen different groups were evaluated, seven groups of males (aged on average 36.86 months, $\mathrm{SD}=4.90$ ) and eight of females (aged on average 39.31 months, $\mathrm{SD}=5.44$ ).

\section{Procedure}

Each session was conducted on a classroom floor area of $16 \mathrm{~m}^{2}$ (see Figure 5). First, a researcher showed the participants how the robot could be controlled by the sticks. Then, each kid in a group picked a stick, so that each one of them was in charge of a motion command, and practiced for one minute putting the foam shape close to the RFID reader and watching the robot move/stop accordingly. Once they had finished familiarizing themselves with the robot, they were asked to walk the robot from one point to another in the work space, where a Wall-E toy was placed. It was explained to them that they had to help the mobile robot reach its static plush friend, who was waiting for him so that they could play together. Once they made it reach its destination, the target toy was placed in a different location repeating this interaction 9 times for each group. A teacher supervised, guided, and encouraged the kids while they were playing, while two researchers took notes on the children's behaviors and impressions. After the session, the teacher, who knew the children's personalities and had experience in interpreting their behaviors and emotional states, reviewed the researchers' notes and completed or corrected them.

\section{Method}

Product of a previous discussion with the instructors, several observational dimensions were considered during the course of the activity regarding emotional, social, and interaction issues:

- Positive impressions: including all the pleasant and favorable reactions of the children towards the platform, namely, excitement, non-stop desire (i.e., not wanting the activity to stop), interest about the robot's technology, and astonishment.

- Negative impressions: consisting of all unpleasant reactions to the activity, such as frustration when they wanted the robot to move and failed to give the command properly, shyness, and lack of interest in the game.

- Social behaviors: According to Parten [22], at the age of 2-3, children start to play side by side in the same activity in what she calls "associative play", which produces certain social involvement, until they learn how to collaborate. Hence, it is interesting to see how socialization and collaboration emerge when using the platform.

- Interaction patterns: referring to specific interaction strategies that children exhibited during game play.

- Usability problems: evaluating the main sources of interaction errors in our platform during the course of the activity.

- Task completion: If the task is not successfully completed, this dimension provides general insights into the fundamental reasons for failure.

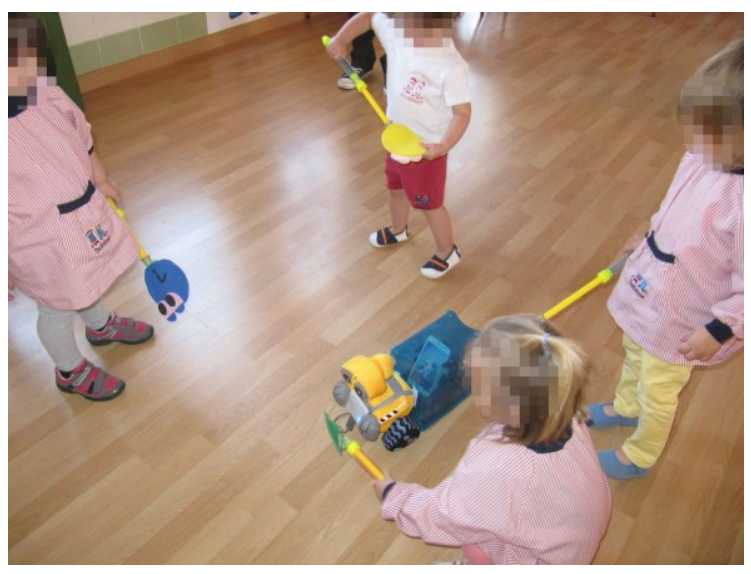

Figure 5. Kids playing with the robot during the experiment 


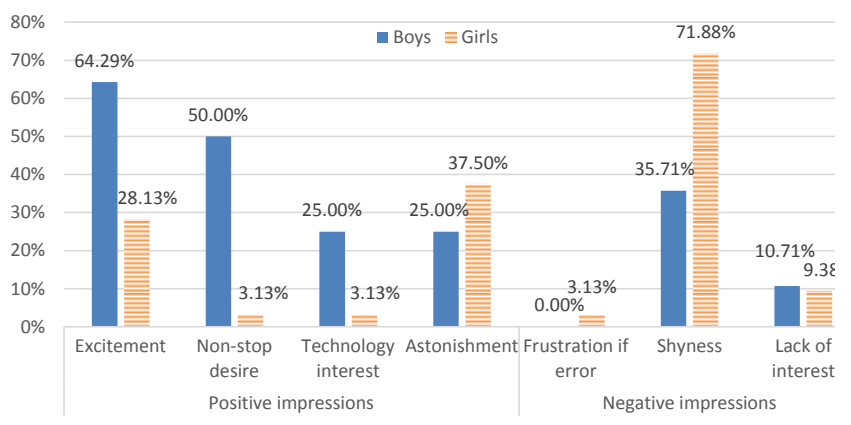

Figure 6. Positive and negative impressions observed in individuals (grouped by gender)

\section{Observational Findings}

The kids played for a period of 10 to 24 minutes ( $\mathrm{M}=15.0$, $\mathrm{SD}=3.92$ ), except for one group of boys that had to stop after 6 minutes because two of them started kicking the robot and the plush toy.

\section{Emotional Issues}

The first general impression observed during all sessions was the existence of some gender differences. In this respect, as shown in Figure 6, girls were shyer than boys when first approaching the robot, namely, they kept their distance and required the teacher to encourage them to make a first contact with the device. They also did not speak much during the course of the activity. One girl even refused to participate and had to be replaced by another classmate. However, this feeling was mitigated once they were introduced to the robot and watched it move, where some smiles appeared and shyness was, in some cases, replaced by astonishment (this impression was also more frequent in girls). The overall impression was that children had high levels of flow, as defined by Nakamura and Csikszentmihalyi [20], i.e., the majority of them were fully immersed in a feeling of energized focus, full involvement, and enjoyment in the process of the activity with only $10.71 \%$ of boys and $9.38 \%$ of girls showing a lack of interest in the robot and the activity. In some cases, they tried to move the robot but failed in bringing the stick to the correct place where the RFID reader was located, but hardly any of the kids felt frustrated about this and continued in a mental state of flow, although boys seemed to enjoy the activity more. They were more excited and anxious to play (e.g., one of them, before the researcher finished explaining how the robot moved, took a stick and screamed "I want to, I want to!"). Boys were also more interested than girls on the technological components that composed the robot. They asked about the RFID reader and the smartphone ("There's a phone inside!", "It has a phone, why?"). And, finally, they were also less willing to stop the activity ("Again, again!", "Now where do we put it [the target plush toy]?").

\section{Social Issues}

The social behaviors observed and the proportion of the evaluated groups exhibiting at least one sign of a specific

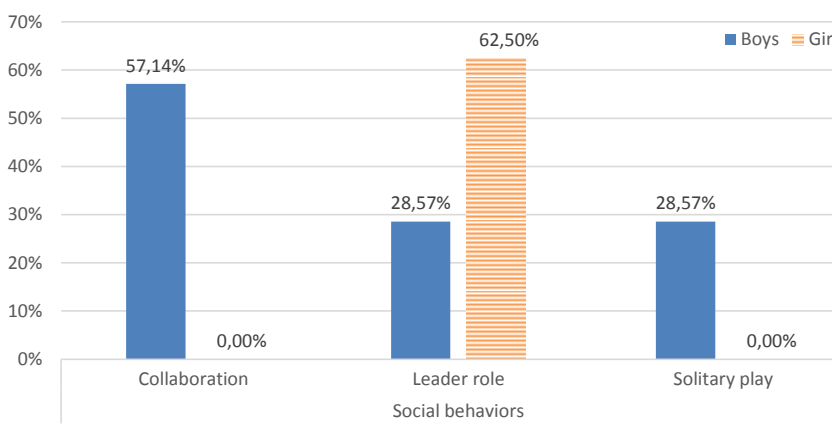

Figure 7. Group Social behaviors observed (grouped by gender)

type of social behavior are summarized in Figure 7. The categorization of the observed behaviors was made in collaboration with children educators. Firstly, in many groups the figure of a leader appeared, who tried to direct the others (sometimes without success), and this was more frequent among girls $(62.5 \%$ of the groups) than boys $(28.57 \%)$ even of similar age. Secondly, $28.57 \%$ of the male groups showed at least one member who did not want to share the interaction with the rest (solitary play in terms of Parten's categorization), but this behavior was not observed in girls. This could suggest a higher degree of maturity among females. Thirdly, it was surprising that none of the female groups showed any trace of collaboration between its members, although this was a frequent behavior observed among the male groups $(57.14 \%)$. Some traits of collaboration observed among the boys were: helping and correcting one another (e.g., a kid saying "Not like that" to another when the latter brought the stick to the wrong place), or coordinating their actions in order to complete the task ("Now you!", “Me, me, me!”, "stop it!”, “don’t turn, it goes by itself").

The observed interpersonal skills were discussed with educators who confirmed these categories were consistent with everyday play with traditional toys in the classroom context. In addition, it is interesting to consider the work by Parten [22] in observing and describing how social play develops in preschool children. In her studies she described development of social play into six categories: unoccupied behavior, onlooker behavior, solitary play, parallel play, associative play, and cooperative play. The first two categories are considered to be non-play behavior, and the last three are indicators of social participation. In terms of this categorization we may conclude that our platform enables associative and cooperative play because, as stated by Parten, the child plays with other children, the communication concerns the common activity, all the members engage in a similar activity and the group is organized in terms of different roles for the purpose of making some material product or striving to attain some competitive goal. 


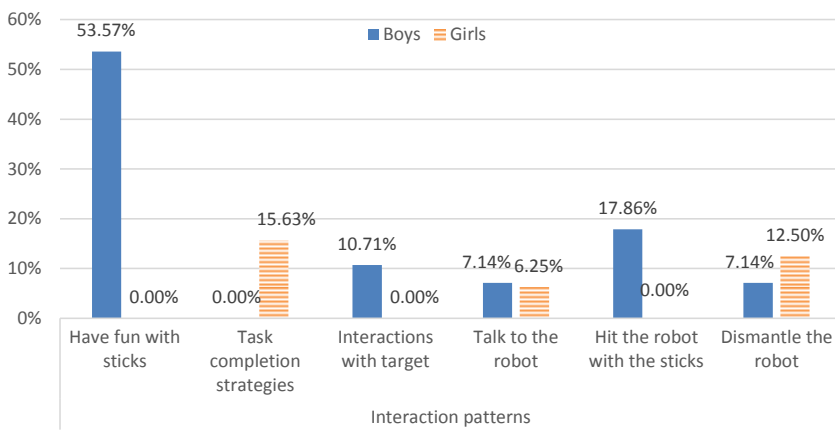

Figure 8. Individual interaction patterns (grouped by gender)

\section{Interaction Issues}

Besides performing the basic interactions to move the robot, other types of interaction were observed (see Figure 8). Although not very frequently, some boys and girls $(7.14 \%$ and $12.5 \%$, respectively) stopped playing and removed the protective plastic case from the robot in order to inspect the contents. Nevertheless, the kids were mostly focused on the task at hand, and a few of them were so immersed in the activity they started complementing the commands given with the sticks with oral instructions: "Come here, here!", "Turn, turn, turn!" Other differences were observed between boys and girls: whereas the latter were more patient, the former were generally more nervous and wanted to be constantly controlling the robot. With respect to this, $15.63 \%$ of the girls showed some strategic behaviors in order to complete the task, such as looking at the target while making the robot turn in order to know when they were facing each other so they could stop turning. On the other hand, some of the boys $(10.71 \%)$ were so eager to use their sticks that they got confused and tried to give commands to the plush-only target instead of the electronic robot, because another boy was actually at that time interacting with the latter. Another reason supporting this claim of boys being more nervous and active than girls is that more than half of them $(53.57 \%)$ had fun sword fighting with the sticks when they were not controlling the robot (e.g., it was moving forward or it was being controlled by someone else), and $17.86 \%$ of them repeatedly hit the robot with the sticks.

Regarding usability problems, the main reasons for interaction errors were also analyzed, and, as shown in Figure 9, the main reason for boys failing on giving a command to the robot was they were all interacting at the same time, which happened in $71.43 \%$ of the groups. This is probably related to boys being more active and nervous than girls, as explained previously. Also, in $14.29 \%$ of the groups there was at least one interaction that did not succeed because the boys blocked the robot with their own bodies once they had given it a command (e.g., by putting their foot on the same side they wanted the robot to turn to). Girls' interaction errors, however, were equally due to all of them interacting at once and placing the stick somewhere else than in front

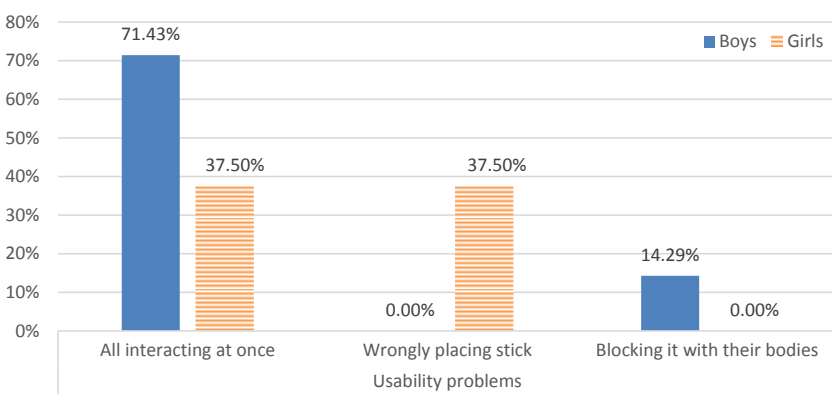

Figure 9. Usability problems (grouped by gender)

of the RFID reader (e.g., on the robot's head, back, etc.). This error, however, did not occur among the boys.

\section{Task Completion}

On average, the task of making the robot meet the plush toy was successful $71.43 \%$ of times for the boys, and $69.44 \%$ for the girls. However, when they failed it was mainly due to three reasons: the kids not knowing what to do, losing interest in the game, or holding and moving the robot manually without using tangible elements. The main reasons for the boys were, as Figure 10 depicts, not knowing what to do in $42.86 \%$ of the groups (e.g., the robot went into a wall and they did not know how to correct its course because the RFID reader was not accessible), and, to a lesser extent, losing interest in the task. The groups of girls presented higher percentages of these reasons than the boys. In $62.50 \%$ of them there was at least one case where they stood idly not knowing what interaction to perform next, in $37.50 \%$ of the groups lack of interest happened in one or more tasks, and, finally, in $12.50 \%$ of the groups there was a girl who did not make use of the sticks, and took the target and moved it to the robot, hence claiming she had completed the task.

\section{GENERAL DISCUSSION}

The previous results can be analyzed according to several dimensions.

Firstly, it should be considered how effectively the technology can keep children in the mental state of flow which several studies recognize as a key factor in promoting learning. In this respect we may conclude that the platform was

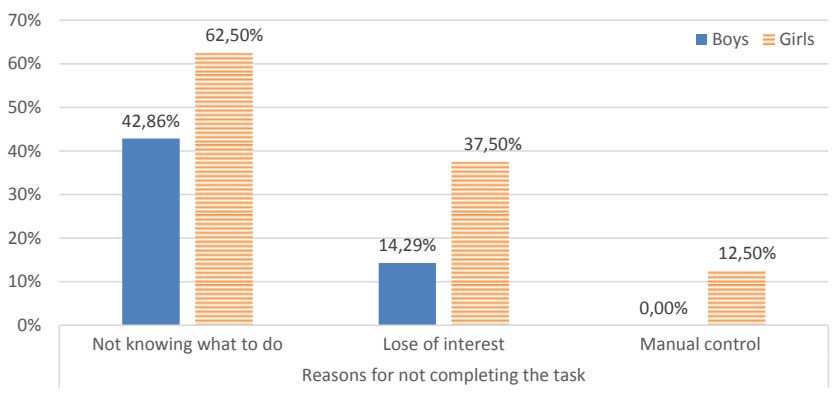

Figure 10. Reasons for not completing the task (grouped by gender) 
positively perceived by most children, who showed signs of amusement and stayed focused during the activity. Boys, however, showed a more explicit attitude towards the platform, as revealed by higher levels of physical spontaneity and joy, a higher number of observable complaints about having to leave the game, and a higher number of inquiries about the robot's underlying technology. This is consistent with previous studies that analyzed gender differences in playful behavior among kindergarten children [37]. This study reveals that boys are rated significantly higher than girls in measures of physical spontaneity and manifest joy. The fact that boys showed higher levels of interactivity with the robot is also validated by previous research, which suggests that girls tend to be more passive than boys, often playing inside [26] and are more likely to exhibit sedentary, constructive play [25] while boys prefer to engage in gross motor and functional play [24]. Nevertheless, despite these previous works, it must be taken into account that gender behaviors may also be influenced by other factors such as parental gender stereotypes, previous experiences with technology, and previous experiences of the boys in the class.

Secondly, some interesting observations need to be discussed here on aspects of collaborative coordination and social behavior. Whereas girls showed a more hierarchical strategy, in which a "leader" emerged and directed the task (although their instructions were not necessarily heeded), boys showed more collaboration traits. This observation is not consistent with previous research [5] which found that boys' social interactions tend to be focused on dominance, with the role of a leader very often present, whereas girls have a stronger convention for turn taking with peers in decision making. This is also confirmed by Thorne [33], who found that boys' play is usually hierarchical in nature, whereas girls' games are usually collaborative. However, these results were observed with older elementary school children, in whom, according to Lever $[11,12]$, sex differences emerge in the formation and organization of play. Therefore, it remains to be confirmed whether the social organization and roles observed in our experiment can be generalized for the earlier stages of development (prekindergarten and kindergarten). In this respect, further research with a higher number of groups needs to be done in order to confirm or refute this hypothesis.

It is also worth noting that in our experiment boys also showed a more dominant attitude, since they were more prone to conflicts with respect to having exclusive access to the robot's functionality. This agrees with previous research [23], which found girls more likely than boys to express behaviors that mitigate a conflict, whereas boys are more likely to exhibit different forms of heavy-handed behavior to resolve conflicting situations.

Thirdly, in terms of task completion and interaction problems it has to be pointed out that, even though the children were able to complete most of the tasks, there were some cases in which they did not know how to proceed, e.g., when the robot walked into a wall and made the RFID reader inaccessible. Some mistakes were also observed in girls concerning the correct placement of the stick when giving the robot a command. These mistakes more often observed in girls may be related to two cognitive issues. In the first place, as discussed in [35], the findings of numerous studies demonstrate that male children typically outperformed females in spatial ability tests, including spatial perception. In the second place, this may also be related to boys being usually engaged in more physical and spatial play, whereas girls are more involved in pretense (imaginary or simulated) game. i.e., they prefer fantasy play without the benefit of realistic props [3].

Finally, another dimension worth considering is the educators' impressions. These generally expressed excitement about the platform and the possibility of using it as a support in their everyday classroom activities. Most of them acknowledged technology as a great motivating element for very young children. As a teacher expressed, it is very easy to capture their attention "simply by waving a paper in the air", but keeping them focused is more challenging. Technological devices cause attraction, hence retaining the kids' attention for longer periods of time. Furthermore, when they were asked whether this effect was caused by the devices per se or simply by being introduced to something new, some interviewees answered that, although the novelty factor had an important effect on the attraction, it did not seem to be crucial, because most children were already used to dealing with technological devices such as smartphones or tablets, and these still had the same captivating effect on them. Regarding our prototype in particular, some teachers remarked this platform would cause an interesting change of paradigm in their way of presenting new knowledge to the kids. In their opinion, this would be done in a more effective way by increasing children's focus on the activity. Almost all the educators praised the versatility of the platform, which could be used to teach a great variety of educational subjects and be used to make group activities (in contrast to using other more private devices such as tablets). Furthermore, some of them also appreciated the tangibility of the interactions in terms of being simple and understandable without requiring complex configurations on a digital display that would force educators to concentrate on the technology instead of on the children.

\section{CONCLUSIONS AND FUTURE WORK}

In this paper we have presented the iterative design of a mobile robot controlled by a TUI to be used in the context of kindergarten educational activities. We have taken into account the insights and actual needs of nursery teachers in order to refine the design of the platform, and an evaluation has been made with actual children in order to test its usability. The results seem to indicate the platform causes high excitement among them, mostly in boys, and they generally have fun with it, in a permanent state of flow. In addition, the majority of them are able to complete the tasks, which is 
a reason to believe that the interaction is simple and intuitive enough for kindergarten children. Teachers also report good acceptance towards implanting the system in their classrooms, and they also foresee many activities that could be conducted with it, which makes this platform useful and versatile for kindergarten instruction.

In future work, we would like to explore in depth some of the behaviors observed, such as the relation between the appearance of a leader and collaboration between participants. Also, it would be interesting to go deeper into evaluating the goodness of the tangibility of the interaction versus remotely controlling the robot via other mechanisms, such as direct touch on a tablet or using a joystick, and also to study the effect on the experience of the shape of the tangible sticks compared to other different objects or materials. Furthermore, taking into account the educational activities proposed by the educators, more complex tasks will be devised in order to test whether the platform actually contributes to improving the learning of kindergarten children.

\section{ACKNOWLEDGEMENTS}

This work is funded by the European Development Regional Fund (EDRF-FEDER) and supported by Spanish Ministry of Economy and Competitiveness with Project TIN2014-60077-R, and from Universitat Politècnica de València under Project UPV-FE-2014-24. It is also supported by fellowship ACIF/2014/214 within the VALi+d program from Conselleria d'Educació, Cultura i Esport (Generalitat Valenciana), and by fellowship FPU14/00136 within the FPU program from Spanish Ministry of Education, Culture and Sport.

We would like to thank the Universitat Politècnica de València ${ }^{2}$, the Ituitu ${ }^{3}$, and the Bambinos ${ }^{4}$ kindergarten schools for their collaboration during the development of this study.

\section{REFERENCES}

1. Diana Africano, Sara Berg, Kent Lindbergh, Peter Lundholm, Fredrik Nilbrink, and Anna Persson. 2004. Designing Tangible Interfaces for Children's Collaboration. CHI '04 Extended Abstracts on Human Factors in Computing Systems, ACM, 853-868. http://doi.org/10.1145/985921.985945

2. Alissa N. Antle. 2013. Exploring how children use their hands to think: an embodied interactional analysis. Behaviour \& Information Technology 32, 9, 938-954. http://doi.org/10.1080/0144929X.2011.630415

3. Jennifer Connolly, Anna Beth Doyle, and Flavia Ceschin. 1983. Forms and Functions of Social Fantasy Play in Preschoolers in M.B. In Social and Cognitive

\footnotetext{
2 http://ampa.blogs.upv.es/

3 http://ituitu.es/

${ }^{4}$ http://www.escuelainfantilbambinos.com/
}

Skills: Sex Roles and Children's Play. Academic Press, New York, 71-92.

4. Amnon Dekel, Galit Yavne, Ela Ben-Tov, and Yulia Roschak. 2007. The spelling bee. Proceedings of the International Conference on Advances in Computer Entertainment Technology, ACM, 212-215. http://doi.org/10.1145/1255047.1255092

5. Janet A. DiPietro. 1981. Rough and tumble play: A function of gender. Developmental Psychology 17, 50 58. http://doi.org/10.1037/0012-1649.17.1.50

6. Allison Druin. 2002. The role of children in the design of new technology. Behaviour \& Information

Technology 21, 1, 1-25. http://doi.org/10.1080/01449290110108659

7. Madhumita Ghosh and Fumihide Tanaka. 2011. The impact of different competence levels of care-receiving robot on children. IEEE International Conference on Intelligent Robots and Systems, IEEE, 2409-2415. http://doi.org/10.1109/IROS.2011.6048743

8. Juan Pablo Hourcade, Michael Crowther, and Lisa Hunt. 2007. Does mouse size affect study and evaluation results?: a study comparing preschool children's performance with small and regular-sized mice. Proceedings of the 6th International Conference on Interaction Design and Children, ACM, 109-116. http://doi.org/10.1145/1297277.1297300

9. Juan Pablo Hourcade. 2007. Interaction Design and Children. Foundations and Trends in Human-Computer Interaction 1, 4, 277-392.

http://doi.org/10.1561/1100000006

10. C. Lorelle Lentz, Kay Kyeong-Ju Seo, and Bridget Gruner. 2014. Revisiting the Early Use of Technology: A Critical Shift from "How Young is Too Young?" to "How Much is 'Just Right'?" Dimensions of Early Childhood 42, 1, 15-23.

11. Janet Lever. 1976. Sex Differences in the Games Children Play. Social Problems 23, 4, pp. 478-487.

12. Janet Lever. 1978. Sex Differences in the Complexity of Children's Play and Games. American Sociological Review 43, 4, pp. 471-483.

13. Susan C. Levine, Janellen Huttenlocher, Amy Taylor, and Adela Langrock. 1999. Early sex differences in spatial skill. Developmental Psychology 35, 4, 940-949. http://doi.org/10.1037/0012-1649.35.4.940

14. Liang-Yi Li, Chih-Wei Chang, and Gwo-Dong Chen. 2009. Researches on using robots in education. Proceedings of the 4th International Conference on ELearning and Games, Springer Berlin Heidelberg, 479482. http://doi.org/10.1007/978-3-642-03364-3_57

15. Min Liu. 1996. An exploratory study of how prekindergarten children use the interactive multimedia 
technology: implications for multimedia software design. Journal of Computing in Childhood Education 7, 1-2, 71-92.

16. Javier Marco, Eva Cerezo, and Sandra Baldassarri. 2013. Bringing tabletop technology to all: Evaluating a tangible farm game with kindergarten and special needs children. Personal and Ubiquitous Computing 17, 8, 1577-1591. http://doi.org/10.1007/s00779-012-0522-5

17. Vicente Nacher, Fernando Garcia-Sanjuan, and Javier Jaen. 2015. Game Technologies for Kindergarten Instruction: Experiences and Future Challenges. Proceedings of the 2nd Congreso de la Sociedad Española para las Ciencias del Videojuego, 58-67.

18. Vicente Nacher, Javier Jaen, and Alejandro Catala. 2014. Exploring Visual Cues for Intuitive Communicability of Touch Gestures to Pre-kindergarten Children. Proceedings of the Ninth ACM International Conference on Interactive Tabletops and Surfaces, ACM, 159-162.

http://doi.org/10.1145/2669485.2669523

19. Vicente Nacher, Javier Jaen, Elena Navarro, Alejandro Catala, and Pascual González. 2015. Multi-touch gestures for pre-kindergarten children. International Journal of Human-Computer Studies 73, 37-51. http://doi.org/10.1016/j.ijhcs.2014.08.004

20. Jeanne Nakamura and Mihaly Csikszentmihalyi. 2008. Flow Theory and Research. In Handbook of Positive Psychology. 195-206. http://doi.org/10.1093/oxfordhb/9780195187243.013.00 18

21. Junichi Osada, Shinichi Ohnaka, and Miki Sato. 2006. The scenario and design process of childcare robot, PaPeRo. Proceedings of the 2006 ACM SIGCHI International Conference on Advances in Computer Entertainment Technology, ACM. http://doi.org/10.1145/1178823.1178917

22. Mildred B. Parten. 1932. Social participation among pre-school children. Journal of Abnormal and Social Psychology 27, 3, 243-269. http://doi.org/10.1037/h0074524

23. Kimberly K. Powlishta, Maya G. Sen, Lisa A. Serbin, Diane Poulin-Dubois, and Julie A. Eichstedt. 2001. From infancy through middle childhood: The role of cognitive and social factors in becoming gendered. In Handbook of the psychology of women and gender, Rhoda K. Unger (ed.). John Wiley \& Sons Inc, Hoboken, NJ, USA, 116-132.

24. Kenneth H Rubin, Terrence L Maioni, and Margaret Hornung. 1976. Free play behaviors in middle- and lower-class preschoolers: Parten and Piaget Revisited. Child Development 47, 2, 414-419. http://doi.org/10.2307/1128796
25. Kenneth H. Rubin. 1977. Play Behaviors of Young Children. Young children 32, 6, 16-24.

26. Anne B. Smith and Patricia M. Inder. 1993. Social Interaction in Same and Cross Gender Preschool Peer Groups: a participant observation study. Educational Psychology 13, 29-42. http://doi.org/10.1080/0144341930130104

27. Iris Soute and Henk Nijmeijer. 2014. An Owl in the Classroom: Development of an Interactive Storytelling Application for Preschoolers. Proceedings of the 2014 Conference on Interaction Design and Children, ACM, 261-264. http://doi.org/10.1145/2593968.2610467

28. Amanda Strawhacker and Marina Umaschi Bers. 2014. "I want my robot to look for food": Comparing Kindergartner's programming comprehension using tangible, graphic, and hybrid user interfaces. International Journal of Technology and Design Education. http://doi.org/10.1007/s10798-014-9287-7

29. Toshimitsu Takahashi, Masahiko Morita, and Fumihide Tanaka. 2012. Evaluation of a tricycle-style teleoperational interface for children: A comparative experiment with a video game controller. Proceedings of the 21st IEEE International Symposium on Robot and Human Interactive Communication, IEEE, 334-338. http://doi.org/10.1109/ROMAN.2012.6343775

30. Fumihide Tanaka, Bret Fortenberry, Kazuki Aisaka, and Javier R. Movellan. 2005. Plans for Developing Realtime Dance Interaction between QRIO and Toddlers in a Classroom Environment. Procceedings on the 4th International Conference on Development and Learning, IEEE, 142-147. http://doi.org/10.1109/DEVLRN.2005.1490963

31. Fumihide Tanaka and Shizuko Matsuzoe. 2012. Learning Verbs by Teaching a Care-Receiving Robot by Children: An Experimental Report. Proceedings of the 7th Annual ACM/IEEE International Conference on Human-Robot Interaction, ACM, 253-254. http://doi.org/10.1145/2157689.2157781

32. Fumihide Tanaka and Toshimitsu Takahashi. 2012. A tricycle-style teleoperational interface that remotely controls a robot for classroom children. Proceedings of the 7th Annual ACM/IEEE International Conference on Human-Robot Interaction, 255-256. http://doi.org/10.1145/2157689.2157782

33. Barrie Thorne. 1993. Gender Play: Boys and Girls in School. Rutgers University Press.

34. Chau Kien Tsong, Toh Seong Chong, and Zarina Samsudin. 2012. Tangible multimedia: A case study for bringing tangibility into multimedia learning. Procedia Social and Behavioral Sciences 64, 382-391. http://doi.org/10.1016/j.sbspro.2012.11.045 
35. Jie Chi Yang and Sherry Y. Chen. 2010. Effects of gender differences and spatial abilities within a digital pentominoes game. Computers \& Education 55, 1220 1233. http://doi.org/10.1016/j.compedu.2010.05.019

36. Nicola J. Yelland. 1994. The strategies and interactions of young children in LOGO tasks. Journal of Computer Assisted Learning 10, 1, 33-49.

http://doi.org/10.1111/j.1365-2729.1994.tb00280.x

37. Evridiki Zachopoulou, Efthimios Trevlas, and Georgia Tsikriki. 2004. Perceptions of gender differences in playful behaviour among kindergarten children.

European Early Childhood Education Research Journal $12,1,43-53$.

http://doi.org/10.1080/13502930485209301 